Original Articles

\title{
Composite index of anthropometric failure (CIAF): A better indicator of overall burden of undernutrition among primary school children
}

\author{
*Gopal Chandra Mandal ${ }^{1}$, Kaushik Bose ${ }^{2}$ \\ Sri Lanka Journal of Child Health, 2021; 50(2): 194-199
}

\begin{abstract}
Introduction: The three conventional indices were insufficient to measure overall prevalence of child undernutrition and hence it was proposed to construct a Composite Index of Anthropometric Failure (CIAF).
\end{abstract}

Objectives: To evaluate the overall burden of undernutrition using CIAF in primary school children of a rural area in West Bengal, India.

Method: A cross sectional study was carried out among 618 children (304 boys and 314 girls) from Government aided primary schools of Bali Gram Panchayat, Arambagh, Hooghly District, West Bengal, India.

Results: Prevalence of undernutrition measured by CIAF was $66.3 \%$ in comparison to $32.5 \%$ stunting, $57.1 \%$ underweight and $40.5 \%$ wasting, three conventional parameters.

Conclusions: CIAF is considered as a single measure which provides the overall burden of under-nutrition in studied population and represents the higher prevalence when compared with the three conventional measures used separately.

DOI: http://dx.doi.org/10.4038/sljch.v50i2.9553

${ }_{1}^{1}$ Associate Professor and Head, Department of Anthropology, Bangabasi College, Kolkata, India, ${ }^{2}$ Professor, Department of Anthropology, Vidyasagar University, Paschin Midnapore, West Bengal, India

*Correspondence: golmal_anth@rediffmail.com

https://orcid.org/0000-0002-0558-3247

(Keceived on 23 March 2020: Accepted after revision on 22 May 2020)

The authors declare that there are no conflicts of interest

Funding: University Grants Commission, Govt. of India, in the form of Minor Research Project in favour of GCM

Open Access Article published under the Creative Commons Attribution CC-BY (c) (i) License
(Key words: Stunting, underweight, wasting, CIAF, primary school children, West Bengal, India).

\section{Introduction}

Studies have shown that nutritional deficiencies and poor health in primary school children can cause low school enrolment, high absenteeism, early dropouts and poor academic performance ${ }^{1}$. Undernutrition is a factor contributing to high child mortality in developing countries ${ }^{2}$. Chronic child undernutrition is associated with slower cognitive development ${ }^{3}$. Increased attention should be paid to the quality of survivors. Nutritional status is a good index of this quality ${ }^{4}$. In the infant and young child, growth assessment best defines health and nutrition $^{5,6}$. Anthropometric assessments are reliable estimates of undernutrition prevalence ${ }^{8}$. Hence anthropometry is mandatory in any study on child health and nutrition ${ }^{7,8}$. Low income, poor healthcare and illiteracy cause and sustain undernutrition in India 9 . Shakhya et al studied 5 governmental primary schools in Nepal and detected over $61 \%$ undernutrition ${ }^{10}$. In Meerut, India, over $49 \%$ urban primary school children were underweight ${ }^{11}$. Today, overweight and obesity, too, are a matter of concern among school children $^{12}$. Svedberg P. noted that conventional indices were insufficient to measure overall prevalence of child undernutrition and proposed the construction of a Composite Index of Anthropometric Failure (CIAF) ${ }^{13}$.

\section{Objectives}

To evaluate the overall burden of undernutrition using CIAF in primary school children of a rural area in West Bengal, India.

\section{Method}

Area of study: The 15 Government aided Primary Schools of Bali Gram Panchayat, Arambagh, Hooghly District, West Bengal, India. This was a rural area and the villages were remote. Most villagers were Hindu by religion.

Study population: A total of 618 rural Bengalee Hindu primary school children, 304 boys and 314 girls within the age range 5-11 years.

Measurements: Heights and weights of primary school children were measured using standard techniques ${ }^{14}$. 
Height was measured using Martin's anthropometer (Variety Mechanical, Kolkata, India). Each subject was requested to stand on bare feet as straight as possible on the standing floor with heels together so that the weight of the subject was distributed evenly on both feet and the head was positioned in the Frankfort Horizontal plane (Eye-Ear plane). The arms hung freely by the sides of the trunk, with the palm facing the thighs. The subjects were asked to keep the heels together in such a way that the medial borders of the feet were at an angle of about $60^{\circ}$, with both heels touching the standing floor. The subjects were asked to take a deep breath and hold it and maintain a fully erect position without altering the load on the heels. The anthropometer was placed behind the subject so that its lower end stood between the heels and the beam passed vertically between the buttocks and touched the back of the head. The horizontal arm of the anthropometer was brought down on the top of the median plane on the head and measurement was recorded to the nearest $0.1 \mathrm{~cm}$. The weighing machine (Equinox-BR-9201, Kolkata, India) was placed on a firm, flat surface. The participants were asked to remove any coats, heavy sweaters, shoes, keys or heavy pocket contents. The participants were also asked to stand in the middle of the scale's platform with the body weight equally distributed on both feet. The participants were weighed to the nearest $0.1 \mathrm{~kg}(100 \mathrm{~g})$. The weighing machine was checked from time to time to set zero. Analyses: Technical errors of measurements (TEM) were within reference values ${ }^{15}$ and hence not incorporated in statistical analysis. Stunting, underweight and wasting were used to assess the nutritional status of the children and CIAF for the total children. National Centre for Health Statistics $^{16}$ (age and sex specific -2 z-scores) defined stunting, underweight and wasting. The classification of children with anthropometric failure (CIAF) is shown in Table 1.

Table 1: Classification of children with anthropometric failure (CIAF)*

\begin{tabular}{|c|c|c|c|c|}
\hline Group name & Description & Wasting & Stunting & Underweight \\
\hline A & No failure & No & No & No \\
\hline B & Wasting only & Yes & No & No \\
\hline C & Wasting and underweight & Yes & No & Yes \\
\hline D & Wasting, stunting and underweight & Yes & Yes & Yes \\
\hline E & Stunting and underweight & No & Yes & Yes \\
\hline F & Stunting only & No & Yes & No \\
\hline Y & Underweight only & No & No & Yes \\
\hline
\end{tabular}

* Classification following Nandy et al., 2005.

The CIAF excludes children in group A and counts all children in groups $\mathrm{B}, \mathrm{C}, \mathrm{D}, \mathrm{E}, \mathrm{F}$ and $\mathrm{Y}$. It therefore provides a single measure with which to estimate the overall prevalence of undernutrition. Svedberg originally suggested six subgroups of anthropometric failure (A to F). However, Nandy et $a l^{17}$ identified an additional subgroup $\mathrm{Y}$.

Ethical issues: Ethical clearance was obtained from the Institutional Ethical Committee Vidyasagar University, West Bengal, India (No. VU/Anth/DC 21/2017). Written informed consent was obtained from the teachers of the children participating in the study.

\section{Results}

A total of 618 rural Bengalee Hindu Primary School children comprising 304 boys and 314 girls within the age group 5-11 years were considered. There were 32 children aged 5 years (boys 15, girls 17), 94 children aged 6 years (47 in each sex), 129 children aged 7 years (boys 58, girls 71), 151 children aged 8 years (boys 73, girls 78), 126 children aged 9 years (68 boys, 58 girls), 71 children aged 10 years (39 boys, 32 girls) and 15 children aged 11 years (boys 04, girls 11). The mean age of the boys was 7.9 years, whereas in case of girls, it was 7.8 years. Table 2 shows the subgroups of anthropometric failure among the studied children.

Table 2: Subgroups of anthropometric failure among the studied children

\begin{tabular}{|l|c|c|c|}
\hline \multirow{2}{*}{ Groups } & \multicolumn{2}{|c|}{ Composite Index of Anthropometric Failure (CIAF) } \\
\cline { 2 - 4 } & $\begin{array}{c}\text { Boys (n=304) } \\
\mathbf{n}(\%)\end{array}$ & $\begin{array}{c}\text { Girls }(\boldsymbol{n}=\mathbf{3 1 4}) \\
\mathbf{n}(\mathbf{\%})\end{array}$ & $\begin{array}{c}\text { Overall }(\mathbf{n}=\mathbf{6 1 8}) \\
\mathbf{n}(\%)\end{array}$ \\
\hline A (No failure) & $99(32.6)$ & $109(34.7)$ & $208(33.7)$ \\
\hline B (Wasting only) & $17(05.6)$ & $27(08.9)$ & $44(07.1)$ \\
\hline C (Wasting and underweight) & $59(19.4)$ & $62(20.4)$ & $121(19.6)$ \\
\hline D (Wasting, stunting \& underweight) & $42(13.8)$ & $33(10.5)$ & $75(12.1)$ \\
\hline E (Stunting \& underweight) & $58(19.1)$ & $53(16.8)$ & $111(18.0)$ \\
\hline F (Stunting only) & $05(01.6)$ & $09(01.5)$ & $14(02.3)$ \\
\hline Y (Underweight only) & $24(07.9)$ & $21(03.4)$ & $45(07.3)$ \\
\hline Total (CIAF, B-Y) & $\mathbf{2 0 5 ( 6 7 . 4 )}$ & $\mathbf{2 0 5 ( 6 5 . 3 )}$ & $\mathbf{4 1 0}(\mathbf{6 6 . 3})$ \\
\hline
\end{tabular}


CIAF showed a $66.3 \%$ prevalence of undernutrition as shown in Table 2. This indicates the actual load of undernutrition among the studied primary school children. Out of the six subgroups of undernourished children (overall - age and sex combined), group C was the highest $(19.6 \%)$, followed by group E (18.0\%), group D (12.1\%), group Y $(7.3 \%)$, group B $(7.1 \%)$ and group F $(2.3 \%)$. Considering the sexes, boys showed a slightly higher prevalence $(67.4 \%)$ than girls $(65.3 \%)$. This sex difference is not statistically significant.
Table 3 represents the prevalence of undernutrition using conventional as well as CIAF parameters. From this table it is clear that the undernutrition prevalence as measured by CIAF is $66.3 \%$ compared $32.5 \%, \quad 57.1 \%$ and $40.5 \%$ to undernutrition prevalence as measured by conventional parameters like stunting (HAZ), underweight (WAZ) and wasting (WHZ) respectively. Furthermore, the three conventional parameters represent the burden of undernutrition separately but in case of CIAF, the actual or total load of undernutrition as a whole is measured.

Table 3: Comparison of the overall prevalence (\%) of undernutrition using various parameters.

\begin{tabular}{|c|c|c|c|c|}
\hline \multirow{2}{*}{ Sex of the children } & \multicolumn{4}{|c|}{ Parameters } \\
\cline { 2 - 5 } & HAZ & WAZ & WHZ & CIAF \\
\hline Boys & $34.2 \%$ & $60.2 \%$ & $39.8 \%$ & $67.4 \%$ \\
\hline Girls & $30.9 \%$ & $54.1 \%$ & $41.1 \%$ & $65.3 \%$ \\
\hline Overall (Sex combined) & $32.5 \%$ & $57.1 \%$ & $40.5 \%$ & $66.3 \%$ \\
\hline
\end{tabular}

HAZ: height for age Z-score, WAZ: weight for age Z-score, WHZ: weight for height Z-score

\section{Discussion}

The prevalence of undernutrition as evaluated by conventional measures reflected comparatively low percentages. The three indicators viz. stunting, underweight and wasting actually measured prevalence separately. No one parameter can reflect the overall prevalence of undernutrition like CIAF where, assemblages of these categories consider the population as a whole. Through CIAF one can estimate the burden of undernutrition as a whole and it always represents a much higher prevalence. Here also we found the same thing (Table 3). More or less similar prevalence of undernutrition measured by CIAF were observed in the study by Das and Bose ${ }^{18}$ in Purulia District of West Bengal $(66.3 \%)$ and Seetharaman et $a l^{19}$ in Tamilnadu (68.6\%). A study among 1-12 year old children resident in Darjeeling district, West Bengal, India by Sen and Mondal $^{20}$ observed the prevalence of undernutrition in the form of wasting, stunting and underweight to be respectively $21.5 \%, 43.3 \%$ and $52 \%$. This increased to $63.6 \%$ using the CIAF, which reflects the similar trend with that of the present study. Das and Bose ${ }^{18}$ studied Bauri children from Purulia District, West Bengal and reported 39.2\% stunting, 51.2\% underweight and $26.6 \%$ wasting. CIAF showed a $66.3 \%$ prevalence of undernutrition, Mukhopadhyay and Biswas ${ }^{21}$ reported $69.1 \%$ prevalence of undernutrition using CIAF in tribal children from Bankura District, West Bengal.

Whereas, a very high level (98.2\%) of undernutrition by CIAF measurementwas noted in the Dakshina Kannada region of Karnataka ${ }^{22}$, $80.3 \%$ was noted in the Bankura District of West Bengal $^{23}$ and in the same place among the ICDS children the CIAF was $73.1 \%{ }^{24}$. A little bit lower prevalence of CIAF was noted among the children from rural Varanasi ${ }^{25}(62.5 \%)$, and from children $(61.3 \%)$ of Sagar Block, South 24 Paraganas, West Bengal $^{26}$. Much lower prevalence $(32.7 \%)$ of overall undernutrition (CIAF) was reported by Dasgupta $\mathrm{A}$, et $a 2^{27}$ among the children of rural Bengal, India where the prevalence of underweight and wasting was $17.7 \%$ but it was $32.7 \%$ when considering CIAF as predictor of undernourishment. Anjum F, et a ${ }^{28}$ worked among the 5-9 years old Kashmiri children and observed a prevalence of $25.6 \%$ of CIAF which is less than that of the current study. Among them, $10.7 \%$ were underweight, $15.3 \%$ were wasted and $8.9 \%$ were stunted. A study among the Bhumij children from Odisha conducted by Goswami $\mathrm{M}^{29}$ revealed that the overall age and sex combined prevalence of stunting, underweight and wasting recorded were $32.4 \%, 42.6 \%$ and $25 \%$ respectively, and CIAF showed a much higher prevalence of undernutrition $(54.4 \%)$.

Prevalence of CIAF was $38.7 \%$ in Bahawalpur region of Pakistan ${ }^{30} ; 33.3 \%$ in Nyanza Province of Kenya $^{31}$ and $55.5 \%$ in Zambia ${ }^{32}$. In all these studies it is evident that the prevalence as computed using CIAF was better single predictor of overall burden of undernutrition.

\section{Conclusions}

CIAF is considered as a single measure which provides the overall burden of under-nutrition in the studied population and it represents the higher prevalence when compared with the three conventional measures used separately.

\section{Acknowledgements}

All study participants are gratefully acknowledged. We especially thank the Primary School authorities of the region, the University Grants Commission, 
and Government of India, for the financial assistance in the form of a Minor Research Project.

\section{References}

1. WHO Expert Committee on Comprehensive School Health Education and Promotion. Promoting Health through Schools. 1997. Report of a Geneva, WHO Technical Series, No. 870.

2. Pelletier DL. The relationship between child anthropometry and mortality in developing countries: implications for policy, programs and future research. Journal of Nutrition 1994; 124: 2047S$2081 \mathrm{~S}$.

3. Scrimshaw NS. 1996. Nutrition and Health from Womb to Tomb, Nutrition Today. 31. https://doi.org/10.1097/000172851996030 00-00004

4. Sachdev HPS. 1995. Assessing child malnutrition: some basic issues. Bulletin of the Nutrition Foundation of India.

5. Waterlow JC, Buzina R, Keller W, Lane JM, Nichman MZ, Tanner JM. The prevention and use of height and weight data for comparing the nutritional status of group of children under the age of 10 year. Bulletin of the World Health Organisation 1977; 55: 489-98.

6. World Health Organization Working Group. Use and interpretation of anthropometric indicators of nutritional status. Bulletin of the World Health Organisation 1986; 64: 929-41.

7. Marins, VMR, Almeida RMVR. Undernutrition Prevalence and Social Determinants in Children aged 0-59 months. Niterol, Brazil. Annals of Human Biology 2002; 29: 609-18.

https://doi.org/10.1080/030144602101401 76

PMid: 12573077

8. Martin-Prevel Y, Delpeuch F, Trassac P, Massamba JP, Adoua-oyila G, Couderet $\mathrm{K}$, Treche $\mathrm{S}$. Determination in the nutritional status of young children and their mothers in Brazzaville, Congo, following the 1994 devaluation of the CFA franc. Bulletin of the World Health Organisation 2000; 78: 108-18.
9. Osmani SR. Nutrition and Poverty. Clarendon Press, Oxford. 1992.

https://doi.org/10.1093/acprof:oso/978019 8283966.001 .0001

10. Shakhya SR, Bhandary S, Pokharel PK. Nutritional status and morbidity pattern among governmental primary school children in Eastern Nepal. Kathmandu University Medical Journal 2004; 2(4): 307-14.

11. Neelu S, Bhatnagar M, Garg SK, Chopra H, Bajpai SK. Nutritional status of urban primary school children in Meerut. The Internet Journal of Epidemiology 2010; $8(1)$ : https://doi.org/10.5580/f01

12. Sidhu S, Kaur N, Kaur R. Overweight and obesity in affluent children of Punjab. Annals of Human Biology 2006; 33 (2): 255-9.

https://doi.org/10.1080/030144606005786 31

PMid: 16684697

13. Svedberg P. 2000. Poverty and undernutrition: theory, measurement and policy. New Delhi: Oxford India Paperbacks.

https://doi.org/10.1093/0198292686.001.0 001

PMCid: PMC91973

14. Lohman TG, Roche AF, Martorell R. Anthropometric Standardization Reference Manual. Chicago: Human Kinetics Books. 1988.

15. Ulijaszek SJ, Kerr DA. Anthropometric measurement error and the assessment of nutritional status. British Journal of Nutrition 1999; 82(3): 165-77. https://doi.org/10.1017/S00071145990013 48

PMid: 10655963

16. International Institute for Population Sciences. 2007. National Family Health Survey (NFHS-3), 2005-06: India: Volume I. Mumbai, India: IIPS; (http://www.rchiips.org/nfhs/report.shtml, accessed on 26.12.2019)

17. Nandy S, Irving M, Gordon D, Subramanian SV, Smith GD. Poverty, child undernutrition and morbidity: new 
evidence from India. Bulletin of the World Health Organisation 2005; 83(3):210-6.

18. Das S, Bose K. Report on "anthropometric failure" among rural 2-6 years old Indian Bauri caste children of West Bengal. Anthropological Review 2009; 72: 81-8. https://doi.org/10.2478/v10044-008-00171

19. Seetharaman N, Chacko TV, Shankar SRL, Mathew AC. Measuring malnutrition - the role of Z-scores and the Composite Index of Anthropometric Failure (CIAF). Indian Journal of Community Medicine 2007; 32(1): 35-9. https://doi.org/10.4103/0970-0218.53392

20. Sen J, Mondal N. Socio-economic and demographic factors affecting the Composite Index of Anthropometric Failure (CIAF). Annals of Human Biology 2012; 39(2):129-36.

https://doi.org/10.3109/03014460.2012.65 5777

PMid: 22324839

21. Mukhopadhyay DK, Biswas AB. Food security and anthropometric failure among tribal children in Bankura, West Bengal. Indian Pediatrics 2011; 48(4): 311-4. https://doi.org/10.1007/s13312-011-00572

PMid: 21169653

22. Brahmbhatt KR, Hameed S, Naik PM, Prasanna KS, Jayram S. Role of new anthropometric indices, validity of MUAC and Weech's formula in detecting undernutrition among under-five children in Karnataka. International Journal of Biomedical and Advance Research 2013; 3(12): 896-900.

https://doi.org/10.7439/ijbar.v3i12.872

23. Shit S, Taraphdar P, Mukhopadhyay DK, Sinhababu A, Biswas AB. Assessment of nutritional status by composite index for anthropometric failure: a study among slum children in Bankura, West Bengal. Indian Journal of Public Health 2012; 56(4): 305-7.

https://doi.org/10.4103/0019557X.106421 PMid: 23354144

24. Mandal G, Bose K. Assessment of overall prevalence of undernutrition using composite index of anthropometric failure (CIAF) among preschool children of West
Bengal, India. Iranian Journal of Pediatrics 2009; 19(3): 237-43.

25. Anwar F, Gupta MK, Prabha C, Srivastava RK. Malnutrition among rural Indian children: An assessment using web of indices; International Journal of Public Health and Epidemiology 2013; 2(4): 7884.

26. Biswas S, Giri SP, Bose K. Assessment of nutritional status by composite index of anthropometric failure (CIAF) : a study among preschool children of Sagar Block, South 24 Paraganas District, West Bengal, India. Anthropological Review 2018; 81(3): 269-77.

https://doi.org/10.2478/anre-2018-0022

27. Dasgupta A, Parthasarathi R, Prabhakar VR, Biswas R, Geethanjali A. Assessment of undernutrition with Composite Index of Anthropometric Failure (CIAF) among under-five children in a rural area of West Bengal. Indian Journal of Community Health 2014; 26(2): 132-8.

28. Anjum F, Pandit MI, Mir AA, Bhat IA. Z score and CIAF - A comprehensive measure of magnitude of under nutrition in a rural school going population of Kashmir, India. Global Journal of Medicine and Public Health 2012; 1(5):46-9.

29. Goswami M. Prevalence of undernutrition measured by Composite Index of Anthropometric Failure (CIAF) Among the Bhumij Children of Northern Odisha, India. Journal of the Nepal Paediatric Society 2016; 36(1): 61-7.

https://doi.org/10.3126/jnps.v36i1.14390

30. Khan REA, Jamal WN. Determinants of under-nutrition of primary school-age children: a case study of urban bahawalpur. Paper presented at: ISOSS 2009. Proceedings of the 5th International Conference on statistical sciences, mathematics, statistics and applications. 23-25; Lahore, Pakistan. 2009. (http://www.isoss.net/downloads/Proc5thc onf.pdf \#page $=291, \quad$ accessed on 25.12.2019)

31. Berger MR, Fields-Gardner C, Wagle A, Hollenbeck CB Prevalence of malnutrition in human immunodeficiency virus/acquired immunodeficiency 
syndrome orphans in the Nyanza province of Kenya: a comparison of conventional indexes with a composite index of anthropometric failure; Journal of the American Dietary Association 2008; 108(6) : 1014-7.

https://doi.org/10.1016/j.jada.2008.03.008

PMid: 18502236
32. Lekprichakul T, Umetsu C, Yamauchi T. Child growth as a measure of household resilience: A re-examination of child nutrition situation using new growth reference standard. Vulnerability and resilience of social-ecological systems, FR3 Project report; 98. 2010.

(http://www.chikyu.ac.jp/resilience/files/R eportFY2009/FullReport2009.pdf\#page=1 00 , accessed on 25.12.2019). 